\title{
Cultivation of Subconsciousness and Its Training Effect in Physical Education Teaching and Training
}

\author{
Xiaoyan Hou (iD) ${ }^{1}$ and Kongmei Dong ${ }^{2}$ \\ ${ }^{1}$ Department of Physical Education, Huzhou Vocational and Technological College, Huzhou 313000, Zhejiang, China \\ ${ }^{2}$ Department of Military Sports, Jiangxi Agricultural University, Nanchang 330000, Jiangxi, China \\ Correspondence should be addressed to Xiaoyan Hou; houxiaoyan@hzvtc.net.cn
}

Received 5 December 2021; Revised 4 January 2022; Accepted 13 January 2022; Published 11 February 2022

Academic Editor: Haibin Lv

Copyright (c) 2022 Xiaoyan Hou and Kongmei Dong. This is an open access article distributed under the Creative Commons Attribution License, which permits unrestricted use, distribution, and reproduction in any medium, provided the original work is properly cited.

\begin{abstract}
The detection and tracking technology of moving human body is a hot and difficult point in the research of computer vision technology. Most of the current human body tracking systems use PC as the basic framework, through the calculation and analysis of the video data obtained by the camera. Subconscious is the consciousness that exists in our mind, but we do not realize it. It can stimulate the potential of athletes through the cultivation of subconsciousness, so that athletes can achieve better results. The main purpose of this paper is to explore the training and training effect of subconsciousness in physical education teaching and training. This paper mainly introduces the overview of subconsciousness, the characteristics of subconsciousness, and the cultivation of subconsciousness in physical education training. In this paper, from the track and field major of our school, we selected 48 people whose physical fitness is basically the same, and the results of 400-meter and 800-meter races are similar. The 48 people were randomly divided into four groups: control group 1, control group 2, subconscious group 1, and subconscious group 2. Control group 1 and control group 2 were given traditional physical education for 3 months, while subconscious group 1 and subconscious group 2 were given auditory stimulation for 3 months. Three months later, the physical fitness test, 400-meter race results, and 800-meter race results of the two groups of students were compared and analyzed. The experimental results show that, after three months of physical education training, the results of B1 group and B2 group in $400 \mathrm{~m}$ race were $52.35 \mathrm{~s}$ and $51.98 \mathrm{~s}$, respectively. The results of group B1 and group B2 were $1.6 \mathrm{~s}$ and $1.8 \mathrm{~s}$ faster than those of group A1 and group A2 in the $400 \mathrm{~m}$ race, and the scores were increased by $3.1 \%$ and $3.4 \%$, respectively. The average scores of physical fitness test of the subconscious group and the control group were 79.39 and 69.85 , respectively. The average score of the physical fitness test of the subconscious group was 9.5 points higher than that of the control group, and the score was increased by $9.54 \%$. It is proved that the cultivation of subconsciousness in physical education teaching and training can stimulate students' interest in sports teaching and training and stimulate students' sports potential, so as to improve the effect of students' sports teaching and training.
\end{abstract}

\section{Introduction}

The fifth-generation mobile communication (5G) must not only achieve explosive growth in data traffic but also solve problems such as large-scale connections and low latency. In order to meet the challenges of large-scale connections and explosive growth rate requirements, 5G wireless access technology needs to be quite flexible and reliable and can further improve the utilization rate of the spectrum. With the rapid improvement of computer storage capacity and computing power, the speed of data generation is getting faster and faster, and the amount of data that people obtain through the network and various electronic devices is increasing. In the era of big data, large-scale data exists in many fields. Embedded systems are based on computer technology and application-centric. In many application scenarios of pattern recognition and machine learning, the extracted feature dimensions are often high, which will lead to complex training models, long training time, and lowefficiency data analysis. Among them, the auditory training content includes the cultivation of the ability to judge sound, the cultivation of auditory attention ability, the cultivation of 
the ability to distinguish different sounds, the cultivation of selective listening ability, and the cultivation of auditory feedback ability.

In the environment of higher education, concept physical education is widely offered to promote a healthy lifestyle. The subconscious is a kind of consciousness that we cannot perceive. Any psychological process is affected by it; we must assume its existence, but at the same time we cannot realize it directly. This psychological process is called subconscious. In sports teaching and training, adding the cultivation of students' subconsciousness can help students adjust the excessive pressure in the face of competition and effectively tap the sports potential of students.

Martin et al. tested the possibility of using consumer level BCI to mine subconscious for face recognition. In an experiment, subjects were asked to see pictures of celebrities in the expectation that $20 \%$ of them would be recognized (consciously); since these photos were pictures of celebrities, Martin et al. predicted that the subjects would see them before $80 \%$ of the people they (consciously) did not know. In addition, Martin et al. predicted that their subconscious will recognize 80 percent of the people they have met before $[1,2]$. Kim et al. studied the neural basis of subconscious, implicit and conscious, explicit core stabilization training (adim), and dynamic neuromuscular stabilization (DNS) in patients with central instability. All participants received conscious adim, conscious hip flexion and extension (adim-hfe), and subconscious HFE and HFE core stability training based on subconscious DNS $[3,4]$.

Merino-Marban et al.'s study was to investigate the effects of one-minute stretch training and five-week stop training on sitting posture and stretching performance of school-age children aged 5-6 years. Subsequently, the participants received a five-week off-duty period. Classic sitting and stretching tests were performed at the beginning and end of the development plan and at the end of the rest period [5]. Jarani et al.'s study was designed to evaluate two school sports (sport based and game based) in Tirana, Albania [6]. Mazurek et al.'s research aims to explore the effect of eightweek routine physical education supplemented with high intensity intermittent cycle exercise (HIIE) or moderate intensity continuous cycle exercise (CME). Anthropometric data, aerodynamics, and anaerobic capacity were measured before and after the 8-week plan [7]. Mayorga-Vega et al.'s study was to explore the effects of physical education based development and maintenance programs on objective and perceived health-related physical health of high school students [8].

The innovation of this paper is as follows: (1) It presents an introduction to the subconscious, which is a mental process that has occurred but has not yet reached the state of consciousness. (2) In terms of training strategies, it is hoped that, in the process of physical education, through giving students positive emotions, the benign conditioned reflex expected by students can be established. (3) Students should be allowed to subconsciously feel the joy of learning sports in the process of learning track and field. (4) This article proposes the cultivation of auditory stimulation subconsciousness, trying to make students maintain positive emotions in physical training, thereby forming a new organized emotional response.

\section{Subconsciousness and Physical Education Teaching}

2.1. Subconsciousness. What is the subconscious? The subconscious is the consciousness that exists in our mind but we do not realize it [9-11]. The subconscious is a mental process that has occurred but has not yet reached the state of consciousness. It is knowledge below the brain threshold $[12,13]$.

2.1.1. The Characteristics of the Subconscious. The functional characteristics of the subconscious are mainly divided into the following points:

(1) Solve Problems Independently. Sometimes we try our best to solve some problems that cannot be solved for a long time. At this time, we think that the unconscious is likely to be awakened by us, and the subconscious will be transformed into subjective consciousness to serve our thinking. The subconscious will automatically arrange and classify the clues you think, and the complete answer to the problem will be obtained from your mind, which is the subconscious automatically solving the problem for you. The manifestation of subconscious autonomous thinking and problemsolving is called inspiration. The subconscious, which is not connected to the problem we are thinking about, is usually located somewhere deep in the brain $[14,15]$.

(2) Influence Behavior. Our subconscious mind controls our daily thoughts, habits, and subconscious activities that we do not even know why we do. For example, when encountering some difficult problems, some people will face difficulties and take specific actions to solve the problems; when others face difficulties, their first reaction is to give up rather than considering how to take specific actions to solve problems. This is the subconscious reaction of different people in the process of life.

(3) Fuzziness and Cryptography. The fuzziness of the subconscious is that some of the information stored in our brain becomes blurred due to time and various reasons. It is only when the subconscious reawakens and processes the information and memory that it becomes readable. The conversion process is so fast that we can hardly detect it. The cryptogenicity of the subconscious is the possibility of arousing our subconscious mind in a specific situation or in a specific command consciousness. It is like entering a password into your brain and opening up the memory that was previously stored.

(4) Storage Memory. The subconscious mind is like a huge warehouse for storing people's thoughts and life experiences. From birth to death, everything we perceive will enter the subconscious, which will be stored in the subconscious 
warehouse. Some familiar scenes, habitual behaviors, and thoughts are all things that we will not actively memorize. They are all in the unconscious state that we enter into our subconscious mind. There is an old saying in China that if you are close to the ink, you will get red; if you are close to the ink, you will get black, which is the result of our subconscious mind.

\subsubsection{The Relationship among Subconsciousness, Precon-} sciousness, and Consciousness. The relationship among subconsciousness, preconsciousness, and consciousness is absolute and relative $[16,17]$. The subconsciousness is the concentration of all our desires, while the preconsciousness is to satisfy the subconsciousness as much as possible under environmental conditions, and the consciousness is to control this behavior according to morals and norms $[18,19]$. Generally speaking, when the enhanced subconscious state exceeds a certain threshold, it can realize the transformation to the conscious state. Subconsciously, it is still relatively weak. Between our subconscious and subconscious, it is called examination for the time being [20, 21]. A check between the subconscious and the subconscious can effectively prevent the destruction and threat of some subconscious minds, while some subconscious minds are not allowed to be more destructive and dangerous [22]. In order to realize the transformation from subconsciousness to consciousness, it usually needs to avoid the second examination and then go through the first examination, once identified and expelled. Although the double examination hinders the subconscious even more, the latter does not stop and its activities continue. Other forms of self-expression, such as negligence, dreams, and psychosis, are derived from the "unconscious" state of human beings, that is, the moment when the level of consciousness and preconsciousness is relaxed $[8,23]$.

2.2. Intense Stimulation. In the usual physical education training, teachers put some slow and pleasant music around the students to relax their subconsciousness and help them adjust their muscle and body functions [24]. When students learn important courses, teachers can stimulate students' hearing and make them have a positive impact on sound in their subconscious, so as to improve the effect of students' learning [25]. Before the competition starts, let the students tell themselves aloud in the open space that I am the best, so as to help the students relieve the heart pressure and strengthen the blood circulation in the body, convert all kinds of bad emotions of the students before the competition into the driving force in the competition [26], so as to help the students play their own level in the competition and even play beyond the level and get a good result. Tell the students that, in the final sprint, shout out to yourself that I am the best [27]. In their usual sports training, they will call up their memory subconsciously and give full play to their level. What should be noted here is that strong stimulation or repeated stimulation is only an auxiliary means and measure and should not be used too much. An irritant refers to a substance that can cause a reversible inflammatory reaction in the eyes, skin, or respiratory mucosa.

2.3. Embedded System. The image processing experiment is a part of the functional module of the client application program of this system. In the unsupervised situation, how to select the distinguishing features is a key issue. The embedded technology model is shown in Figure 1.

Before the moving target is extracted, the system needs to classify the moving human body based on information such as grayscale, texture, and edge after extracting the region of the moving human body first. Grayscale refers to the use of black tones to represent objects; that is, black is used as the reference color, and black with different saturations is used to display the image. In image processing, the edge refers to the part of the pixel set with gray gradient changes. Generally, the gradient value of the texture of the image is relatively small. The gradient of the edge is relatively large; it can be approximated that the edge is a kind of texture, but it cannot be said that the texture is the edge. The main purpose of preprocessing the image is to make relevant improvements and remove image noise after the image is obtained. The method of image enhancement is to add some information or transform data to the original image by certain means, selectively highlight the features of interest in the image, or suppress some unwanted features in the image, so that the image matches the visual response characteristics. Noise cancellation refers to the elimination, weakening, or suppression of random changes in the image. Since the value of the parameter is fixed during the execution of the algorithm, the accuracy of the arithmetic operation accuracy of the main processor can be used to preprocess the correction parameters in advance, and the corresponding lookup table is generated according to the pixel coordinates, and all frames share a lookup table. It can not only reduce the loss of precision but also improve the efficiency of the algorithm. The error values of different cost aggregation functions are shown in Table 1.

Using this algorithm can disperse those with obvious characteristic gray levels into the neighborhood to smooth the image. Signal processing is a general term for processing various types of electrical signals according to various expected purposes and requirements. The signal processing based on the cognitive network cooperation spectrum sharing is expressed as

$$
\begin{aligned}
\chi_{1} & =\sqrt{S_{s}} g_{0} a_{0}+\delta_{s 1}, \\
\chi_{o} & =\sqrt{S_{s}} g_{0} a_{0}+\delta_{o}, \\
\chi_{o, i+1} & =\sqrt{S_{s}} g_{o, i} a_{0}+\delta_{i 1}, \\
\chi_{s 2} & =g_{2} \sum_{i=1}^{O} \sqrt{\varepsilon_{i} S_{o}} a_{i}+\delta_{s 2} .
\end{aligned}
$$

The frequency of signal $a_{0}$ corresponds to $S_{s}$, $\delta_{o}$ represents the time slot, and $g_{0}$ is the target transmission rate. Calculate the time slot signal of any time node, and all satisfy the following formula: 


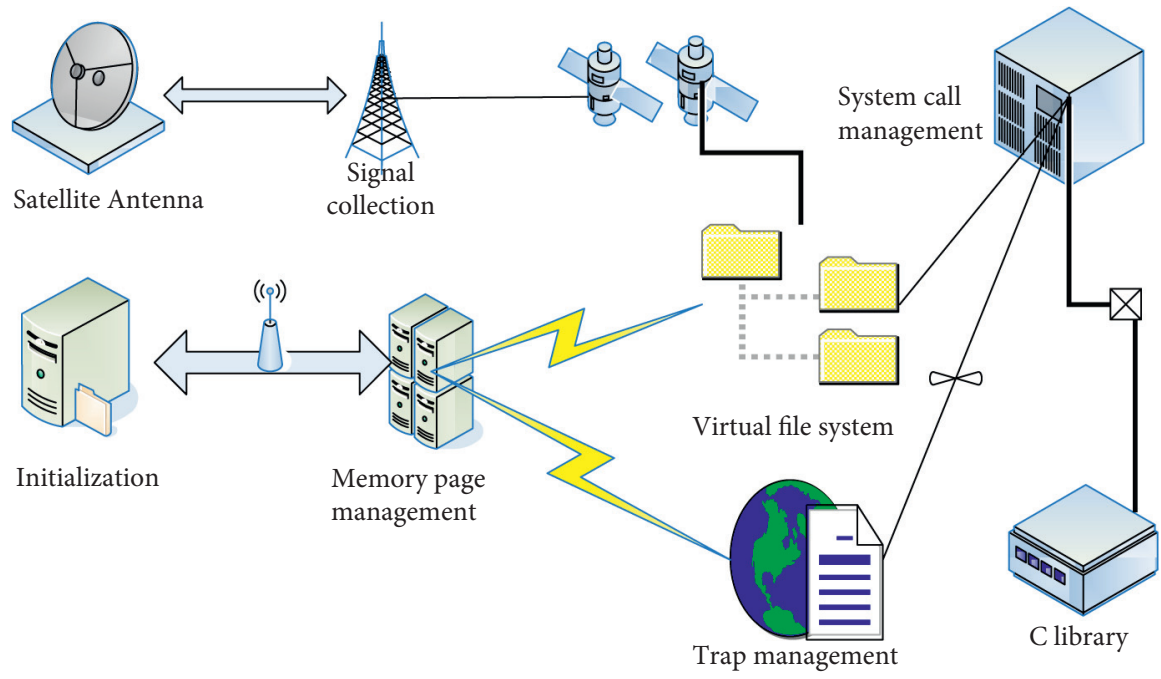

Figure 1: Embedded technology model.

TABLE 1: Function error.

\begin{tabular}{lcc}
\hline Local algorithm & $a$ & $b$ \\
\hline SAD & 8.17 & 8.23 \\
SSD & 10.19 & 10.02 \\
NCC & 10.33 & 10.49 \\
\hline
\end{tabular}

$$
\delta_{i}=\frac{1}{2} \log _{2}\left(1+S_{s}\left\|g_{0}\right\|^{2}+S_{s} \frac{S_{s}\left\|g_{0}\right\|^{2} \eta_{0}}{\left\|g_{0}\right\|^{2}}\right) \sum_{i=1}^{a}+1
$$$$
\chi_{o}, a_{2}=k_{o}
$$

$$
O \sum_{i=1}^{o} \sqrt{\eta_{i} S_{s}} a_{i+1}+\delta o_{2}
$$

When calculating the matching cost of the pixel, $\eta_{o}$ is the white noise of the time slot, $k_{0}$ is the weighted average of the cost of the center, and the bilateral filter is used for processing. Among them, white noise refers to noise with equal noise power spectral density contained in frequency bands of equal bandwidth within a wider frequency range.

$$
\begin{aligned}
K_{k}^{a}(i) & =\sum_{r} \exp \left(-\frac{[i-r]}{\varpi_{g}}\right) \exp \left(-\frac{\|L(i)-L(r)\|}{\omega_{s}}\right) K_{k}(r), \\
K_{k}^{a}(i) & =\sum_{r} \exp \omega(i, r) K_{k}(r) \cdot(i-1), \\
k(a \mid a-1) & =R k(a-1 \mid a-1)+\delta r_{a-1} .
\end{aligned}
$$

In the above equation, $\omega_{g}$ represents the matching cost of the node itself, the sum of the weights of the two nodes is $₫(i, r)$, and the weight between the two points is calculated by $k(a \mid a-1)$. Combine node similarity to get the initial view:

$$
\begin{gathered}
\min _{[0,1]} \frac{F_{i}(s)}{i}, \\
F_{i}(s)=K_{i}+R_{i s}+A_{i}, \\
K_{i o} \leq S_{k, i}\left[\frac{s}{S_{k 1}}\right]+S_{k, i}\left[\frac{s}{S_{k 2}}\right]+\cdots+S_{k, i}\left[\left|\delta_{i}\right|-\sum_{i=1}^{a-1} \frac{s}{S_{k i}}\right] .
\end{gathered}
$$

In the above equation, $S_{k i}$ is the number of priorities, $R_{i s}$ is the feature selection, the comparison calculation of the consistency principle is carried out in the sample set, and the formula is described as

$$
\begin{aligned}
Q\left(e^{1} \neq e^{2}\right) & \geq \min \left\{Q_{c}\left(e^{1}\right), Q_{c}\left(e^{1}\right)\right\}, \\
\max (a, b) & =\sum_{i \in E}\left[e^{1}\left(a_{i}\right)-e^{2}\left(a_{i}\right)\right]^{2}+\sum_{i \in Q}\left(b_{i}, e\left(a_{i}\right)\right), \\
\left\|e^{1}\left(a_{i}^{1}\right)\right\|-e^{2}\left(a_{i}^{2}\right) & \leq \beta_{i}+\varphi_{i} .
\end{aligned}
$$

In the above equation, $a_{i}, b_{i}$ is a subset of the sample set. If it is maximized, it is $\max (a, b)$, and its error rate of $\beta_{i}$ can minimize the experience loss $\varphi_{i}$, and the weighted summation is performed in a nonlinear combination:

$$
\begin{aligned}
C\left(a_{m}, a_{n}\right) & =\sum_{h=1}^{u} C_{c}\left(a_{m}, a_{n}\right), \\
C\left(a_{m}, a_{n}\right) & =\sum_{h=1}^{u} l_{c} C_{c}\left(a_{m}, a_{n}\right), \\
\mu & =\left\{c: c=\sum_{c=1}^{N} l_{c} C_{c}, C>0\right\},
\end{aligned}
$$

where $\sum_{n=1}^{u} C_{c}$ is the weight value, matrix $\mu$ restricts it, $l_{c}$ is a function, and the multilinear solution can be expressed as 


$$
\begin{aligned}
& L\left(a_{m}, a_{n}\right)=\left\{l_{0}+\sum_{c=1}^{N} l_{c} a_{i}^{o} C_{n}\right\}^{m}, \\
& \min (m, n)=\left\|B_{-i}-\sum_{i=1}^{l} A_{i} \chi_{m, n}\right\|^{2}+\phi C,
\end{aligned}
$$

where $L$ is the class standard, $\chi_{m, n}$ is the coefficient of the loss function, and $l_{0}$ is the group. In order to make this process reach a balanced state, use a matrix to describe and limit it: $a_{i}$ $L_{m}$.

$$
\begin{aligned}
J & =\left[x_{1}, x_{2}, \ldots, x_{m}\right]^{v}=B\left(B^{v} B\right)^{-(1 / 2),}, \\
j_{m n} & = \begin{cases}\frac{1}{\sqrt{m_{i}}}, & \text { if } a_{i} \in L_{m}, \\
0, & \text { if } a_{i} \notin L_{m},\end{cases} \\
\|J\|_{m-1, n} & =\sum_{i=1}^{v} \sqrt{\sum_{n m=1}^{i} j_{m n}^{2}}
\end{aligned}
$$

The constraint is the relationship between -1 and 1 .

\section{Experimental Design}

3.1. Experimental Data Collection. The main purpose of this paper is to cultivate and train the subconscious in physical education. In this paper, from the track and field major of our school, we selected 48 people whose physical fitness is basically the same, and the results of 400-meter and 800meter races are similar. The 48 people were randomly divided into four groups: control group 1, control group 2, subconscious group 1, and subconscious group 2. Control group 1 and control group 2 were given traditional physical education for 3 months, while subconscious group 1 and subconscious group 2 were given auditory stimulation for 3 months. Three months later, the physical fitness test, 400meter race results, and 800-meter race results of the two groups of students were compared and analyzed.

Control group 1 was labeled as group A1, control group 2 as group A2, subconscious group 1 as group B1, and subconscious group 2 as

group B2.

The first is to understand the basic situation. The relevant data of teachers and students' understanding of embedded microclasses are shown in Table 2. Students' views on the application of embedded microclasses are shown in Table 3. Among them, $12.5 \%$ of the students think that the embedded microclassroom is suitable before class, $33.3 \%$ of the students think it is suitable in the classroom, and $54.2 \%$ of the students think it is suitable after the class. A survey of students' interest in embedded microclasses is shown in Table 4.

3.2. Experimental Steps. Subconsciousness has a positive impact on physical education teaching and training. It can let students exercise independently and improve their track
TABLE 2: Basic situation.

\begin{tabular}{lcc}
\hline Understand situation & Number of people & Percentage (\%) \\
\hline Know it well & 8 & 16 \\
Generally & 12 & 24 \\
Do not understand & 30 & 60 \\
\hline
\end{tabular}

TABle 3: Students' views on the application of embedded microclasses.

\begin{tabular}{lcc}
\hline & Number of people & Percentage (\%) \\
\hline Before class & 6 & 12.5 \\
In class & 16 & 33.3 \\
After class & 26 & 54.2 \\
\hline
\end{tabular}

TABle 4: Survey of students' interest in embedded microclasses.

\begin{tabular}{lcc}
\hline & Number of people & Percentage (\%) \\
\hline High interest & 32 & 66.7 \\
Generally & 13 & 27.1 \\
Not interested in & 3 & 6.2 \\
\hline
\end{tabular}

and field performance. We need to add the cultivation of students' subconsciousness in physical education teaching and establish good conditioned emotional reflex for students. For the students with poor exercise subconsciousness, we try to replace the bad emotional reflexes by intervening in the cultivation of subconsciousness and establish a new benign conditioned emotional reflex. Therefore, in the training strategy, we hope that, in the process of physical education teaching, by giving students positive emotions, we can establish the benign conditioned reflex that students expect. We should let students in the process of learning track and field subconsciously feel the fun of learning sports. In order to enable students to achieve this goal, this paper puts forward the method of auditory stimulation, trying to make students maintain positive emotions in physical education training, so as to form a new organized emotional response.

The cultivation of subconsciousness in physical education training is as follows:

(1) The teacher collects the past performance of the subconscious group students in the track and field team to confirm the students' mastery of the track and field.

(2) Respect students' interest, develop sports skills, master exercise methods, form the habit of consciously participating in exercise, and form a healthy psychological quality.

(3) In the usual physical education training, teachers put some slow and pleasant music around the students to relax their subconsciousness and help them adjust their muscles and body functions.

(4) After the students complete a stage of physical training, teachers should give positive evaluation and encouragement to the students in this stage of training and set the goals for the next stage for 


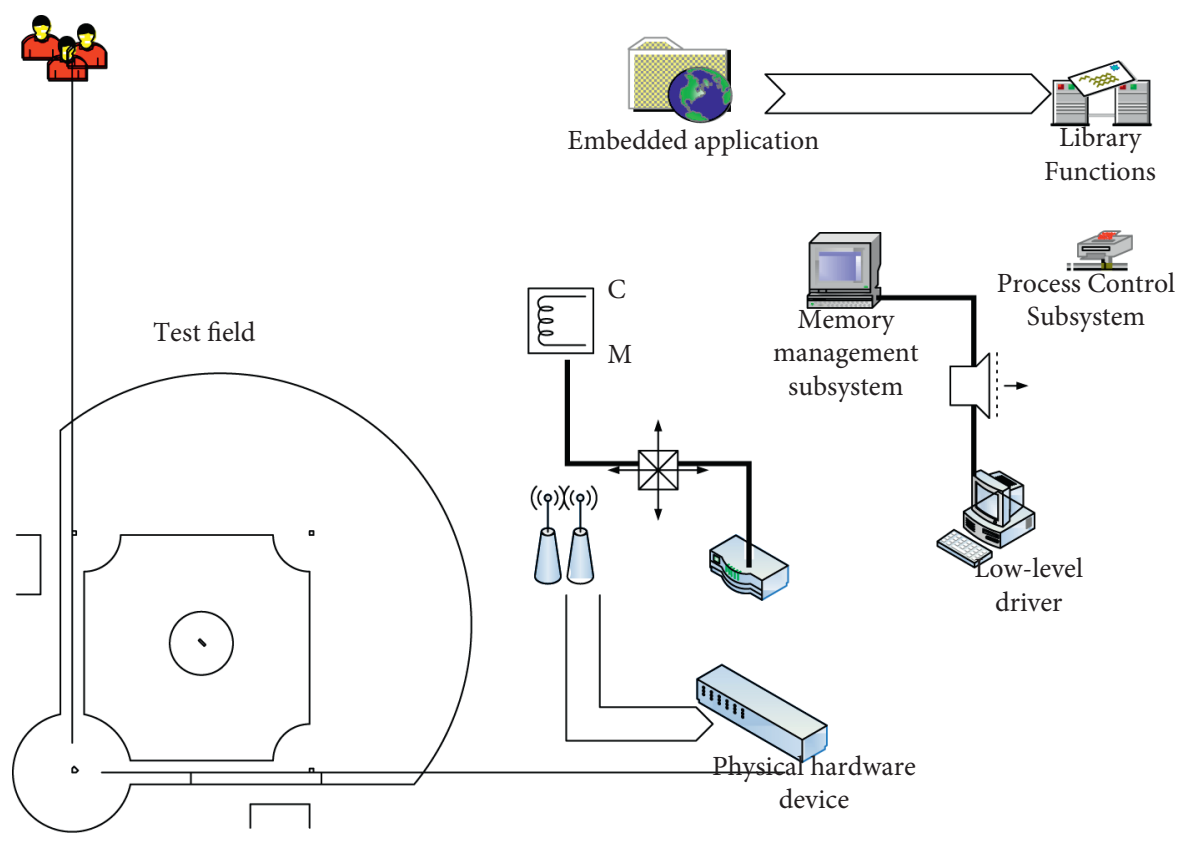

Figure 2: Embedded system and physical education.

students, so that students' subconscious to their own stage of physical education teaching and training in vain improves students' love of sports.

(5) When students learn important courses, teachers can stimulate students' hearing and make them subconsciously have a positive impact on sound, so as to improve the effect of students' learning.

(6) Before the competition starts, let the students tell themselves aloud in the open space that I am the best, so as to help the students relieve the heart pressure, strengthen the blood circulation in the body, and convert all kinds of bad emotions of the students before the competition into the driving force in the competition, so as to help the students play their own level in the competition and even play beyond the level and get a good result.

(7) Tell the students that, in the final sprint, shout out to yourself that I am the best. In their usual sports training, they will call up their memory subconsciously and give full play to their level.

\section{Analysis of Experimental Results}

Having a good body shape, good physical fitness is also the cornerstone of excellent results. Physical quality includes strength quality, speed quality, endurance quality, and agility quality, playing an important role in $400 \mathrm{~m}$. The first moment of running needs to have a strong agility and explosive force along the way to have speed and endurance combination and the final sprint to have explosive force. Therefore, the balance of all aspects of physical fitness is the basis of winning the game. Dreaming is a kind of subconscious release and at the same time an instinctive reaction when encountering a situation; this instinct is not under self-
TABle 5: System simulation parameters.

\begin{tabular}{lc}
\hline Parameter & Value \\
\hline Logarithm & 450 \\
Minimum communication distance & 15 \\
Maximum communication distance & 50 \\
Subchannel bandwidth & 150 \\
Maximum transmit power & 200 \\
Noise power spectral density & -159 \\
\hline
\end{tabular}

control. There are also things that like rhythm. For example, when I hear someone hum or play a song, I will hum without self-learning. This is what the subconscious mind is doing.

4.1. Embedded System. In the process of educational development, technology assists teaching activities with conceptual "soft technology" or material "hard technology" and cultivates qualified talents for the society. Technology affects teaching, and teaching also affects technology. The two are closely integrated, and the degree of mutual fit is getting higher and higher. The process of teaching development is also a process of continuous embedding of technology. The system architecture of the combination of embedded and physical education is shown in Figure 2.

For students, information technology has changed their traditional learning methods, providing them with more learning resources and better conditions for independent learning. $80 \%$ of the total amount of information that people have comes from images. Image information occupies an important position in the various information that can be involved in human activities. Due to its unique structural and spatial characteristics, it cannot be replaced. System simulation parameters are shown in Table 5.

Technology is embedded in teaching, which has a great impact on teaching modes and methods. Data statistics are 
carried out from the three aspects of embedded system's multicore network design, green computing, and trusted computing, as shown in Figure 3. It is generally believed that a green computer is a computer host and related products (including peripherals such as monitors and printers) that conform to the concept of environmental protection and are products with power saving, low noise, low pollution, low radiation, recyclable materials, and ergonomic characteristics. Trusted computing is a technology promoted and developed by the Trusted Computing Group.

Embedded systems use technology to realize the free development of teaching, so that high-quality teaching resources can be delivered to more students through technical means, thereby improving the quality of education. In order to prove this point, the time performance requirements of each image resolution are technically analyzed, as shown in Table 6.

Technological value theory believes that technology carries value, and the pursuit of ethical values such as freedom and justice is carried in the process of using technology. Test from independent tasks, hard real-time tasks, nonperiodic tasks, dynamic priority, online scheduling, and processing allocation are shown in Figure 4. A hard real-time task is a software task process that is applied to a real-time operating system. Dynamic tasks that repeat at any random time and have soft deadlines are called nonperiodic real-time tasks.

According to the convention under the system, the number of parameters is checked, the parameters that do not conform to the regulations are not executed, and the printing information is given to prompt the usage of the command. Different algorithms are used for testing, as shown in Table 7.

4.2. Comparison of the Results of 400-Meter Race between the Subconscious Group and the Control Group before and after the Experiment. The results of $400 \mathrm{~m}$ race in the subconscious group and the control group before and after 3 months are shown in Table 8.

As shown in Figure 5, before the experiment, the results of the four groups of students in the $400 \mathrm{~m}$ race have very little difference, which can be ignored. After 3 months of physical education training, the results of groups B1 and B2 in the $400 \mathrm{~m}$ race were $52.35 \mathrm{~s}$ and $51.98 \mathrm{~s}$, respectively. Compared with three months ago, the results of group B1 and group B2 were $2.79 \mathrm{~s}$ and $2.88 \mathrm{~s}$ faster, respectively, and the results were improved by $5 \%$ and $5.24 \%$. After three months of traditional physical education training, the results of group A1 and group A2 in the $400 \mathrm{~m}$ race were $53.95 \mathrm{~s}$ and $53.78 \mathrm{~s}$, respectively. Compared with three months ago, the results of group A1 and group A2 in the $400 \mathrm{~m}$ race decreased by $0.61 \mathrm{~s}$ and $1.17 \mathrm{~s}$, respectively. After three months of physical education training, the results of group B1 and group B2 were $1.6 \mathrm{~s}$ and $1.8 \mathrm{~s}$ faster than those of groups A1 and $\mathrm{A} 2$, and their scores were increased by $3.1 \%$ and $3.4 \%$. It can be seen that the 400-meter race results of groups B1 and B2 improved more significantly, far better than those of groups $\mathrm{A} 1$ and $\mathrm{A} 2$.

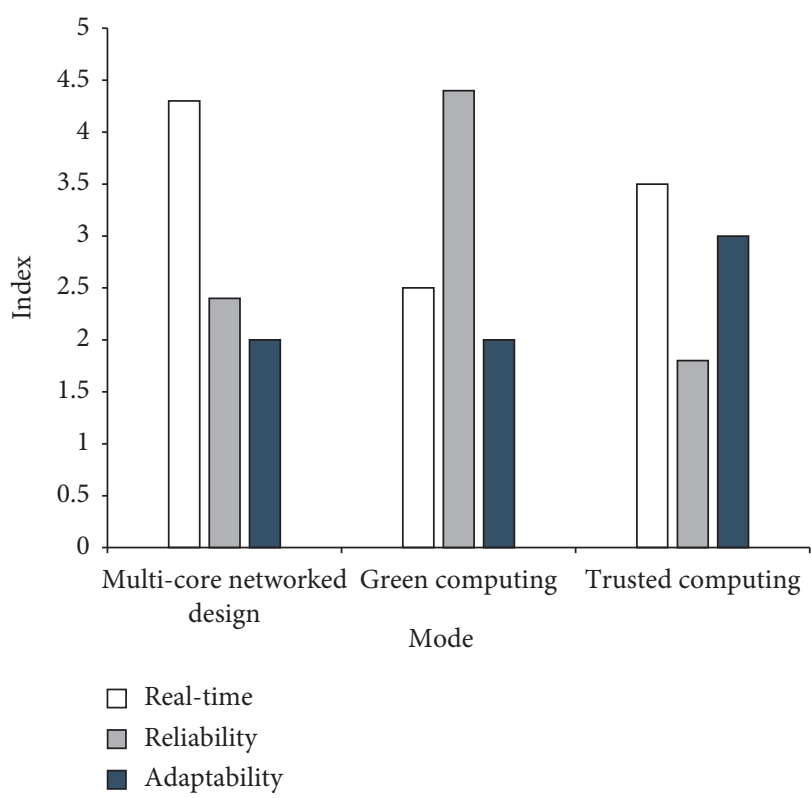

Figure 3: Embedded system.

TABLE 6: Time performance requirements of each image resolution.

\begin{tabular}{lccc}
\hline Serial number & Width & High & Frame rate \\
\hline 1 & 300 & 280 & $150 / \mathrm{s}$ \\
2 & 620 & 340 & $75 / \mathrm{s}$ \\
3 & 1240 & 680 & $40 / \mathrm{s}$ \\
4 & 1680 & 880 & $20 / \mathrm{s}$ \\
\hline
\end{tabular}

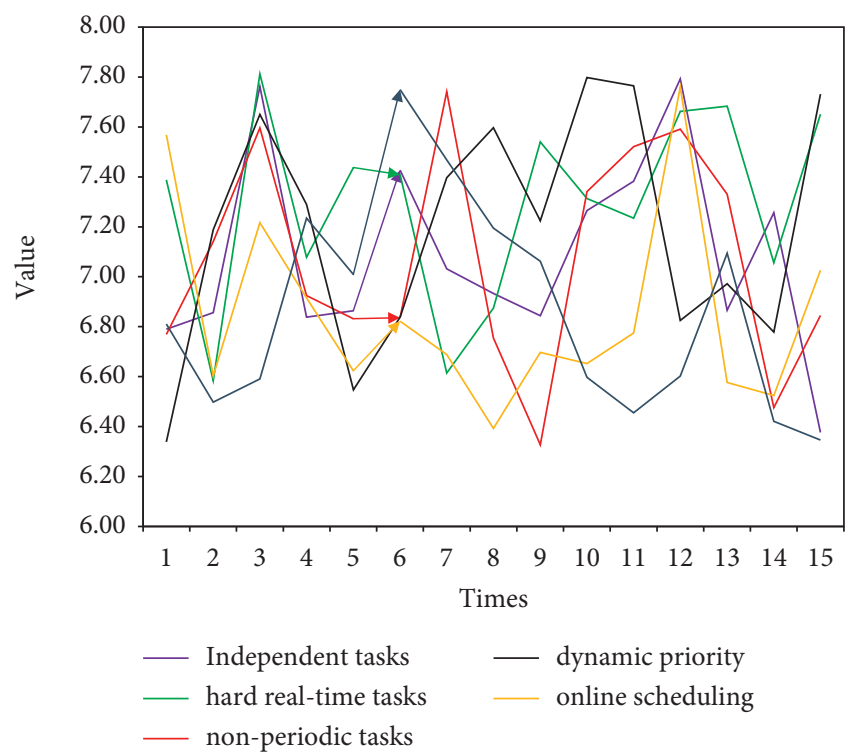

FIGURE 4: Different types of embedded component testing.

4.3. Comparison of $800 \mathrm{~m}$ Race Results between the Subconscious Group and the Control Group before and after the Experiment. Table 9 shows the 800-meter race results of the subconscious group and the control group before and after 3 months: 
TABLE 7: Detection performance parameters of different algorithms.

\begin{tabular}{lcc}
\hline Algorithm & Physiological & Psychology \\
\hline Background difference method & 0.61 & 0.65 \\
Frame difference & 0.77 & 0.69 \\
Vibe algorithm & 0.81 & 0.88 \\
The research algorithm & 0.78 & 0.74 \\
\hline
\end{tabular}

TABLE 8: The results of $400 \mathrm{~m}$ score test in the subconscious group and the control group after the experiment.

\begin{tabular}{lcccc}
\hline \multirow{2}{*}{ Time (s) } & \multicolumn{4}{c}{ Group } \\
& A1 & A2 & B1 & B2 \\
\hline Before the experiment & 54.56 & 54.95 & 55.14 & 54.86 \\
After the experiment & 53.95 & 53.78 & 52.35 & 51.98 \\
\hline
\end{tabular}

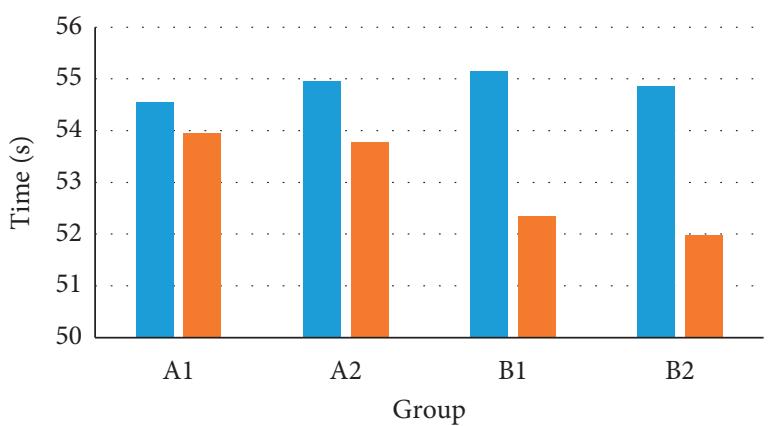

$$
\text { - Before the experiment }
$$$$
\text { - After the experiment }
$$

Figure 5: The results of $400 \mathrm{~m}$ score test in the subconscious group and the control group after the experiment.

As shown in Figure 6, before the experiment, the results of the four groups of students in the 800-meter race have very small differences, which can be ignored. After 3 months of physical education training, the results of groups B1 and B2 in the 800-meter race were $93.56 \mathrm{~s}$ and $94.15 \mathrm{~s}$, respectively. Compared with 3 months ago, the results of group B1 and group B2 were $5.22 \mathrm{~s}$ and $5.11 \mathrm{~s}$ faster, and the results were improved by $5.8 \%$ and $5.15 \%$. After three months of traditional physical education training, the results of group $\mathrm{A} 1$ and group A2 in the $800 \mathrm{~m}$ race are $95.56 \mathrm{~s}$ and $99.13 \mathrm{~s}$, respectively. Compared with three months ago, the results of group A1 and group A2 were $0.44 \mathrm{~s}$ and $0.81 \mathrm{~s}$ faster, respectively, and the improvement range was negligible. After three months of physical education training, the results of group B1 and group B2 were $4.56 \mathrm{~s}$ and $4.17 \mathrm{~s}$ faster than those of groups $\mathrm{A} 1$ and $\mathrm{A} 2$, and the scores were increased by $4.8 \%$ and $4.4 \%$. It can be seen that the cultivation of subconsciousness in physical education training has a great effect on improving students' sports performance.

4.4. Comparison of Physical Fitness between the Subconscious Group and the Control Group. Three months later, the physical fitness evaluation of the subconscious group and the control group is shown in Figure 7.
TABLE 9: The results of $800 \mathrm{~m}$ score test in the subconscious group and the control group after the experiment.

\begin{tabular}{lcccc}
\hline \multirow{2}{*}{ Time (s) } & \multicolumn{4}{c}{ Group } \\
& A1 & A2 & B1 & B2 \\
\hline Before the experiment & 98.56 & 99.13 & 98.78 & 99.26 \\
After the experiment & 98.12 & 98.32 & 93.56 & 94.15 \\
\hline
\end{tabular}

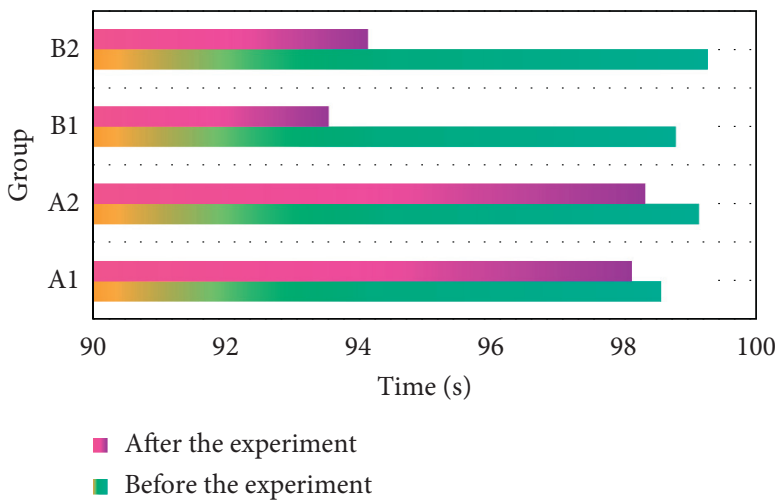

Figure 6: The results of $800 \mathrm{~m}$ score test in the subconscious group and the control group after the experiment.

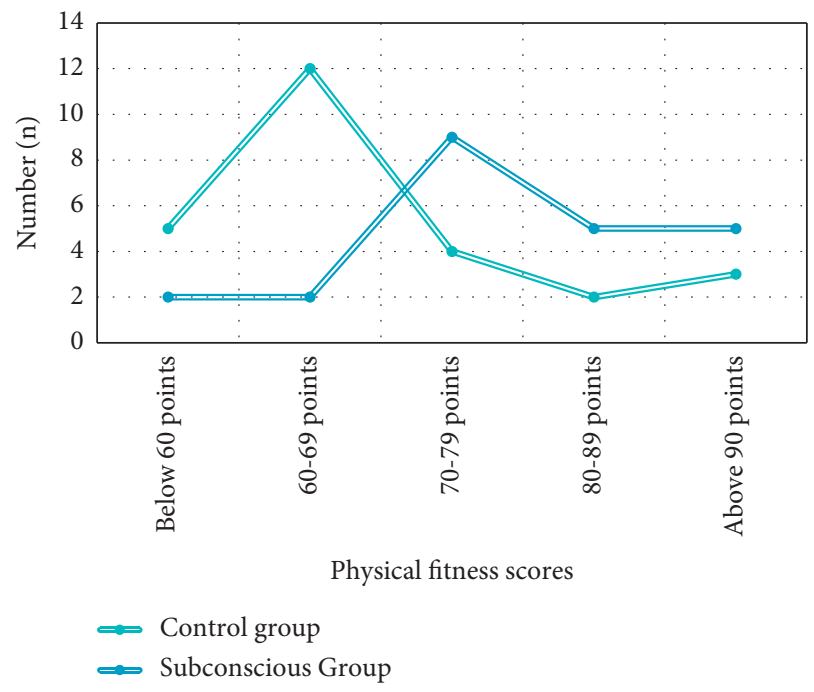

Figure 7: Physical fitness evaluation results of the students in the subconscious group and the control group.

As shown in Figure 7, after three months of physical education training, the numbers of students in the subconscious group whose physical fitness test scores are above $90,80-89$, and $70-79$ are 5,5 , and 9 , respectively. In the control group, there were 3,2 , and 4 students whose physical fitness test scores were above 90, 80-89, and 70-79, respectively. The number of students who scored above 90 in the physical fitness test of the subconscious group was 2 times higher than that of the control group, and the number of students with the score of 80-89 in the subconscious group was 3 times more than that in the control group. After three months of physical education training, the average scores of physical fitness test of the subconscious group and the control group were 79.39 and 69.85 , respectively. 


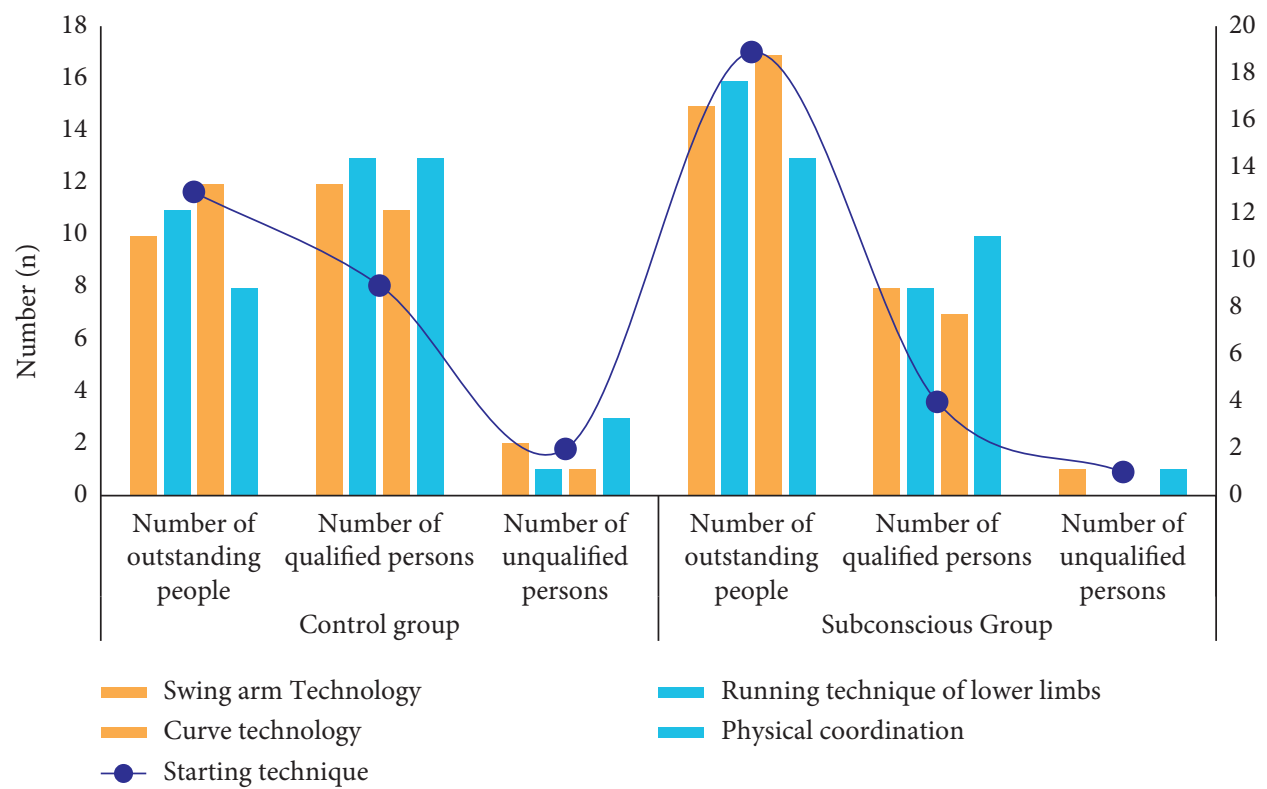

Figure 8: The subconscious group and the control group race technical level test results after the experiment.

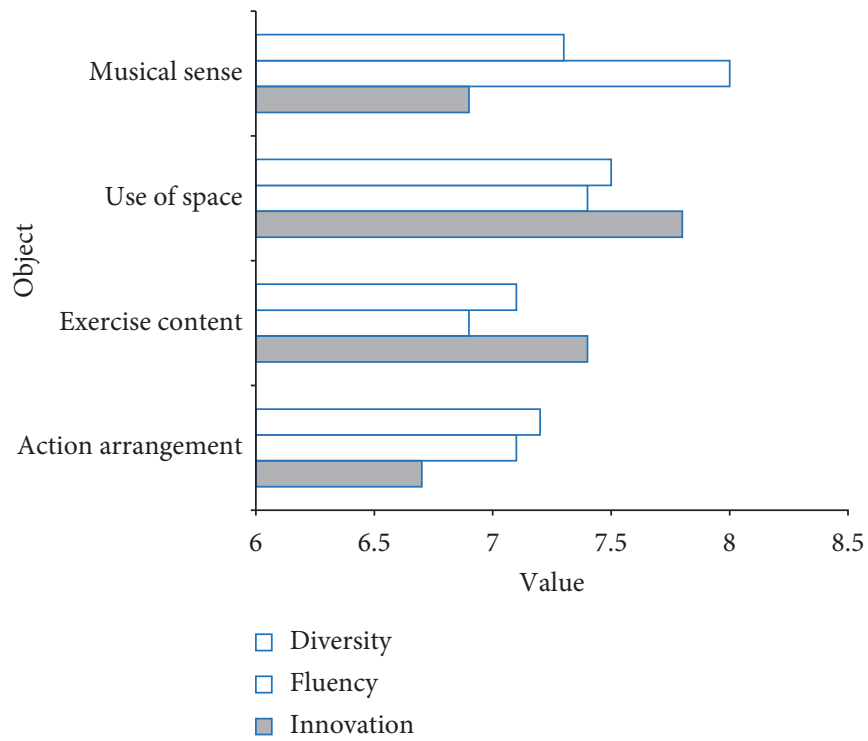

Figure 9: The judging rules of aerobics.

4.5. Comparison of Technical Level between Subconscious Group and Control Group. The comparison of the technical level of the students in the subconscious group and the control group is shown in Figure 8.

It can be seen from Figure 8 that the number of excellent people in the subconscious group is significantly higher than that in the control group. After the subconscious group has received physical education training and the control group has received traditional training, the number of unqualified people has also been reduced to the minimum. In terms of starting skills, there were 19 excellent people in the subconscious group, accounting for $79.16 \%$, while there were only 13 people in the control group, accounting for $54.16 \%$. The number of excellent students in the subconscious group was 6 times more than that in the control group, and the proportion increased by $25 \%$. In terms of physical coordination, the number of excellent people in the subconscious group was 13 , accounting for $54.17 \%$, while that of the control group was only 8 , accounting for $33.3 \%$. The number of excellent students in the subconscious group was 5 times more than that in the control group, and the proportion increased by $20.83 \%$. After a period of physical training, let students stimulate their interest in track and field sports in subconscious training and conduct spontaneous exercise for their own weaknesses. As a result, they have been strengthened at all technical levels, with a significant reduction in the number of unqualified people and a substantial increase in the number of outstanding people. However, because the traditional teaching continues to use the traditional training methods, each athlete cannot be strengthened in their own 


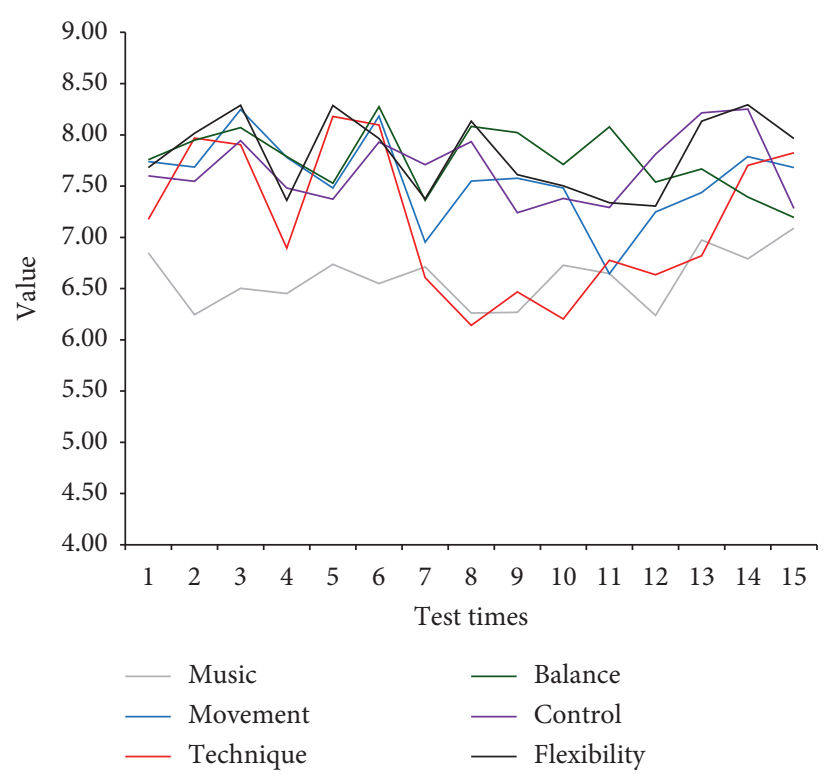

FIgURE 10: Embedded auxiliary effects.

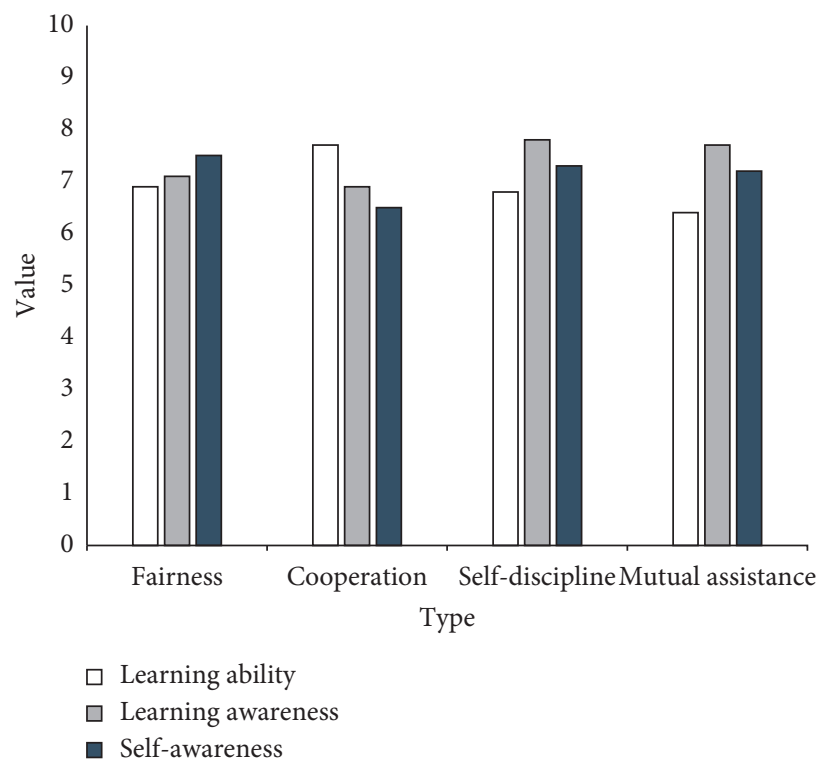

FIgURE 11: Competitive awareness.

shortcomings. Therefore, the number of excellent students and qualified students in the control group is far lower than that in the subconscious group.

Aiming at the performance of the embedded system in image processing, in order to make the difference in the experimental results more obvious, we conduct further analysis on the combination of different physical education teaching and student awareness training. Relevant data for changes in this process are recorded. First, the judging rules of aerobics are shown in Figure 9.

There is almost no research on multimedia teaching methods and their applications, and the media teaching method is very important in the teaching of aerobics in physical education majors in colleges and universities. Multimedia teaching refers to the rational selection and use of modern teaching media through teaching design according to the characteristics of teaching goals and teaching objects in the teaching process. It is organically combined with traditional teaching methods, participates in the whole teaching process together, and acts on students with various media information to form a reasonable teaching process structure to achieve the most optimized teaching effect. The multimedia teaching method is the direction of the future research efforts on aerobics teaching in physical education majors in colleges and universities. The overall situation after the application of the embedded system is shown in Figure 10.

In the entire process of outreach training, teachers mainly play the role of guidance, supervision, and promotion; students are the organizers and implementers of 
specific tasks and become the main body of the classroom. The change data related to competitive awareness is shown in Figure 11.

Experimental data shows that the data analysis platform built by the embedded system can improve students' psychological quality to a certain extent, can enable students to continuously achieve self-transcendence, and can improve the team cohesion of students and improve the awareness of teamwork of basketball players, and it may affect the result of the game. Therefore, based on the embedded system, it is very important to cultivate the subconsciousness of students in physical education training.

\section{Conclusion}

Embedded microclass teaching stimulates students' interest in physical education, encourages students' learning ability, and improves students' academic performance. Subconsciousness is an objective existence. The cultivation of subconsciousness is a conscious psychological control activity in physical education teaching and training. It should start from the following aspects: actively encourage and pay attention to the cultivation of emotional communication, repeated action and racial emotion, hint and imagination training, or repeated cultivation of subconsciousness through strong stimulation.

The main purpose of this paper is to explore the training effect of subconsciousness in physical education teaching and training. This paper mainly introduces the overview of subconsciousness, the characteristics of subconsciousness, and the cultivation of subconsciousness in physical education training. The subconsciousness is a consciousness that exists in our minds but we are not aware of it. We should focus on cultivating the application of the subconsciousness in physical education. In this paper, from the track and field major of our school, we selected 48 people whose physical fitness is basically the same, and the results of 400 -meter and 800 -meter races are similar. The 48 people were randomly divided into four groups: control group 1, control group 2, subconscious group 1, and subconscious group 2. Control group 1 and control group 2 were given traditional physical education for 3 months, while subconscious group 1 and subconscious group 2 were given auditory stimulation for 3 months. Three months later, the physical fitness test, 400meter race results, and 800 -meter race results of the two groups of students were compared and analyzed. The experimental results show that, after three months of physical education training, the results of group B1 and group B2 in the $400 \mathrm{~m}$ race are $52.35 \mathrm{~s}$ and $51.98 \mathrm{~s}$, respectively. Compared with three months ago, the results of group B1 and group B2 were $2.79 \mathrm{~s}$ and $2.88 \mathrm{~s}$ faster, respectively, and the results were improved by $5 \%$ and $5.24 \%$. The results of group $\mathrm{B} 1$ and group B2 were $1.6 \mathrm{~s}$ and $1.8 \mathrm{~s}$ faster than those of group A1 and group A2 in the $400 \mathrm{~m}$ race, and the scores were increased by $3.1 \%$ and $3.4 \%$. The average scores of physical fitness test of the subconscious group and the control group were 79.39 and 69.85 , respectively. The average score of the physical fitness test of the subconscious group was 9.5 points higher than that of the control group, and the score was increased by $9.54 \%$. It can be seen that the cultivation of subconsciousness in physical education training has a great effect on improving students' sports performance. It is proved that the cultivation of subconsciousness in physical education teaching and training can make students full of passion for sports teaching and training, so as to improve the effect of students' sports teaching and training.

In this paper, the method of auditory stimulation in the subconscious is used. The subconscious is incorporated into the physical training teaching, with a very good spirit of innovation. However, due to the lack of certain experience and experimental sample size, the results obtained have certain limitations. The next step of the research content is in-depth analysis of the cultivation of subconsciousness in physical education teaching and training in practice teaching to promote the development of teaching field.

\section{Data Availability}

No data were used to support this study.

\section{Conflicts of Interest}

The authors declare that they have no conflicts of interest.

\section{References}

[1] M. V. Martin, V. Cho, and G. Aversano, "Detection of subconscious face recognition using consumer-grade braincomputer interfaces," ACM Transactions on Applied Perception, vol. 14, no. 1, pp. 1-20, 2016.

[2] D. Micklewright, S. Kegerreis, J. Raglin, and F. Hettinga, "Will the conscious-subconscious pacing quagmire help elucidate the mechanisms of self-paced exercise? New opportunities in dual process theory and process tracing methods," Sports Medicine, vol. 47, no. 7, pp. 1-9, 2017.

[3] D. H. Kim, J. J. Lee, B. S. Han, and J. You, "Cortical or subcortical neural networks during dynamic neuromuscular core stabilization: a fMRI blood oxygen-level dependent (bold) analysis," Journal of Medical Imaging and Health Informatics, vol. 6, no. 7, pp. 1732-1734, 2016.

[4] R. Sholla, K. R. Vyshakh, M. Mohammed, S. Prajwal, and K. R. Pillai, "Leveraging the subconscious mind: transgressing advertisement," Advanced Science Letters, vol. 23, no. 3, pp. 2001-2003, 2017.

[5] R. Merino-Marban, D. Mayorga-Vega, E. Fernandez-Rodriguez, F. V. Estrada, and J. Viciana, "Effect of a physical education-based stretching programme on sit-and-reach score and its posterior reduction in elementary schoolchildren," European Physical Education Review, vol. 21, no. 1, pp. 83-92, 2015.

[6] J. Jarani, A. Grøntved, F. Muca et al., "Effects of two physical education programmes on health- and skill-related physical fitness of Albanian children," Journal of Sports Sciences, vol. 34, no. 1, pp. 35-46, 2016.

[7] K. Mazurek, P. Zmijewski, K. Krawczyk et al., "High intensity interval and moderate continuous cycle training in a physical education programme improves health-related fitness in young females," Biology of Sport, vol. 33, no. 2, pp. 139-144, 2016.

[8] D. Mayorga-Vega, J. Montoro-Escaño, R. Merino-Marban, and J. Viciana, "Effects of a physical education-based programme on health-related physical fitness and its maintenance in high 
school students," European Physical Education Review, vol. 22, no. 2, pp. 243-259, 2016.

[9] H. U. Yingchun, "Identification and analysis of symbolic elements in the mountain tourism," Asian Agricultural Research, vol. 7, no. 9, pp. 78-80, 2015.

[10] M. Vesa, "Book review: werner leodolter digital transformation shaping the subconscious minds of organizations," Organization Studies, vol. 39, no. 8, pp. 1121-1124, 2018.

[11] A. Sussman and J. M. Ward, "Planning for the subconscious," Planning, vol. 82, no. 6, pp. 31-34, 2016.

[12] P. Jackson, "Storm in the womb: exploring the use of private subconscious mind healing (P.S.H. Therapy) in the treatment of hyperemesis gravidarum PART 2," The Australian Journal of Clinical Hypnotherapy and Hypnosis, vol. 37, no. 1, pp. 22-38, 2015.

[13] A. Sweigart-Gallagher and A. C. Thomas, "The location's the thing: endstation theatre and dramaturgies of place," Theatre Topics, vol. 25, no. 1, pp. 25-35, 2015.

[14] R. A. Gray, "Promoting the poetic cause in Ben Okri's stokus from Tales of freedom (2009): original research," Literator, vol. 37, no. 1, pp. 1-10, 2016.

[15] N. J. Lander, L. M. Barnett, H. Brown, and A. Telford, "Physical education teacher training in fundamental movement skills makes a difference to instruction and assessment practices," Journal of Teaching in Physical Education, vol. 34, no. 3, pp. 548-556, 2015.

[16] N. Lander, N. Eather, P. J. Morgan, J. Salmon, and L. M. Barnett, "Characteristics of teacher training in schoolbased physical education interventions to improve fundamental movement skills and/or physical activity: a systematic review," Sports Medicine, vol. 47, no. 1, pp. 135-161, 2017.

[17] C. Pesce, R. Marchetti, R. Forte et al., "Youth life skills training: exploring outcomes and mediating mechanisms of a grouprandomized trial in physical education," Sport, Exercise, and Performance Psychology, vol. 5, no. 3, pp. 232-246, 2016.

[18] S. Wan, L. Qi, X. Xu, C. Tong, and Z. Gu, "Deep learning models for real-time human activity recognition with smartphones," Mobile Networks and Applications, vol. 25, pp. 1-13, 2019.

[19] H. Song and M. Brandt-Pearce, "A 2-D discrete-time model of physical impairments in wavelength-division multiplexing systems," Journal of Lightwave Technology, vol. 30, no. 5, pp. 713-726, 2012.

[20] Y. V. Gordienko, "Theoretical training in physical education of higher educational establishments' girl students," Physical education of students, vol. 19, no. 4, pp. 3-9, 2015.

[21] B. Ruibal-Lista, S. Aranda-García, S. López-García, and J. A. P. Saborit, "Effect of 45-minute CPR training on future physical education teachers," Apunts. Educacion Fisica $y$ Deportes, vol. 138, no. 4, pp. 62-71, 2019.

[22] M. A. Uma and A. B. Palanisamy, "Effect of battle rope training on selected physical and physiological variables among college level athletes physical education," Indian Journal of Applied Research, vol. 5, no. 5, pp. 19-22, 2015.

[23] M. Das and Srinivasan, "Physical education effect of specific preparatory training on selected physiologicalvariables of inter collegiate football players of various positions," International Journal of entific Research, vol. 4, no. 8, pp. 476-479, 2015.

[24] F. Meng, W. Cheng, and J. Wang, "Semi-supervised software defect prediction model based on tri-training," Ksii Transactions on Internet And Information Systems, vol. 15, no. 11, pp. 4028-4042, 2021.

[25] T. T. Sytsma, E. P. Haller, J. W. Youdas et al., "Long-term effect of a short interprofessional education interaction between medical and physical therapy students," Anatomical Sciences Education, vol. 8, no. 4, pp. 317-323, 2015.

[26] C. A. Becerra-Fernandez, M. M. Rafael, and M. V. Daniel, "Effect OF a physical education-based dynamic stretching program ON hamstring extensibility IN female high-school students," Kinesiology, vol. 48, no. 2, pp. 1-9, 2016.

[27] K. Beattie, B. P. Carson, M. Lyons, A. Rossiter, and I. C. Kenny, "The effect of strength training on performance indicators in distance runners," The Journal of Strength \& Conditioning Research, vol. 31, no. 1, pp. 9-23, 2017. 